OPEN ACCESS

Edited by:

James (Jim) David Cotter, University of Otago, New Zealand

Reviewed by:

Thierry Busso,

University of Saint-Etienne, France

*Correspondence:

Billy Sperlich

billy.sperlich@uni-wuerzburg.de

Specialty section:

This article was submitted to

Exercise Physiology,

a section of the journal

Frontiers in Physiology

Received: 30 June 2017

Accepted: 19 July 2017

Published: 14 August 2017

Citation:

Sperlich B and Holmberg H-C (2017)

The Responses of Elite Athletes to

Exercise: An All-Day, 24-h Integrative

View Is Required!

Front. Physiol. 8:564.

doi: 10.3389/fphys.2017.00564

\section{The Responses of Elite Athletes to Exercise: An All-Day, 24-h Integrative View Is Required!}

\author{
Billy Sperlich ${ }^{1 *}$ and Hans-Christer Holmberg ${ }^{2,3,4}$ \\ ${ }^{1}$ Integrative and Experimental Exercise Science, Institute for Sport Sciences, University of Würzburg, Würzburg, Germany, \\ ${ }^{2}$ Swedish Winter Sports Research Centre, Mid Sweden University, Östersund, Sweden, ${ }^{3}$ School of Sport Sciences, UiT The \\ Arctic University of Norway, Tromsø, Norway, ${ }^{4}$ School of Kinesiology, University of British Columbia, Vancouver, BC, Canada
}

Keywords: wearable sensors, training intensity distribution, monitoring, physiological, athletes, biofeedback

The current research topics in Frontiers of Physiology include "Training intensity, volume and recovery distribution among elite and recreational endurance athletes" (Frontiers in Physiology, 2016) and "Wearable Sensor Technology for Monitoring Training Load and Health in the Athletic Population" (Frontiers in Physiology, 2017). As editors of both of these topics, we would like to share some thoughts concerning (a) how they are fundamentally linked and (b) why we believe it is essential to have an all-day, 24-h integrative view to understand elite athletes' responses to exercise.

Athletes who train frequently each week schedule their training and off-training for days (i.e., microcycles, for example, tapering periods, blocks of training) to as long as months (i.e., macrocycles, for example, periods of preparation with different focuses or training camps) to ensure progressive adaptation and prevent fatigue, boredom, and injury. From this perspective, a fundamental goal is to distribute exercise and off-training effectively over a certain period of time (for example, one or several seasons) to achieve optimal adaptation.

Here, we highlight the importance of an all-day, 24-h integrative perspective on training, emphasizing the fact that conditions outside training significantly modulate adaptation, thereby complicating analysis of the distribution of training intensity.

Elite athletes invest a significant amount of time per year in their training, which in some sports amounts to approximately $17 \%$ of their waking time (Fiskerstrand and Seiler, 2004). This means that the remaining $83 \%$ is spent on activities such as recovery, including for example, massage, physiotherapy, medical treatments, eating, as well as activities of daily living (including sitting, lying, working, studying, active, and passive transportation) and social engagements (for example, media, sponsor, and family activities). All of these activities modulate psycho-biological responses to training.

The various approaches for improving recovery include massage (Poppendieck et al., 2016), cooling (Poppendieck et al., 2013), stretching and self-myofascial release (Beardsley and Skarabot, 2015), neuromuscular electrical stimulation (Babault et al., 2011), compression attire (Born et al., 2013), active recovery (Laursen and Jenkins, 2002; Buchheit et al., 2009; Riganas et al., 2015), and many more, and most of these modalities are performed for relatively short periods of time (from minutes to perhaps $1-2 \mathrm{~h}$ or longer) and usually soon after training. Most of these are designed to improve the delivery of oxygen and substrates to muscles and the clearance of metabolites, thereby attenuating or delaying the onset of muscle soreness and rapidly restoring homeostasis, through regulation of growth and transcription factors (Coffey and Hawley, 2007). Clearly, recovery must be taken into account when evaluating the different responses of elite athletes to exercise.

Since moderate-to-light activity (for example, walking or cycling) enhances muscle blood flow, it is surprising that we can find no studies on the influence of physical activity off-training on the biological and psychological outcomes of exercise, especially since the athletic population is alarmingly sedentary when not training (Weiler et al., 2015). 
In addition, other factors such as sleep (Nedelec et al., 2015; Gupta et al., 2017) and nutrition (Thomas et al., 2016) are both influenced by the stress of training and, in turn, modulate the response to training in a significant fashion. In addition, drug abuse by and/or frequent medication of athletes may result in epigenic changes and consequently influence physiological adaptation (Kanherkar et al., 2014). It seems imperative that such factors also be taken into account when comparing different approaches to training.

The busy schedules of (elite) athletes involve a relatively high level of psycho-biological stress, due for example, to frequent traveling for short and long distances, often across time zones (Kölling et al., 2016; Fowler et al., 2017), which detracts from preparedness for subsequent training and competition. More understanding is required here as well.

Moreover, environmental factors, such as exposure to an elevated (Sperlich et al., 2017) or lowered level of oxygen (Girard et al., 2017), variations in temperature (Lorenzo et al., 2010; Kruger et al., 2015), and atmospheric stressors such as ozone, particulate matter (Giles and Koehle, 2014), and ultraviolet radiation, exert an impact on various tissues of the human body and thereby potentially modulate responses to training. Accordingly, such factors should also be considered when judging the responses of elite athletes to exercise.

In addition, psycho-social stress resulting from, for example, media exposure, financial and family concerns, fans, and/or one's own expectations may well influence responses to training.

\section{REFERENCES}

Babault, N., Cometti, C., Maffiuletti, N. A., and Deley, G. (2011). Does electrical stimulation enhance post-exercise performance recovery? Eur. J. Appl. Physiol. 111, 2501-2507. doi: 10.1007/s00421-011-2117-7

Beardsley, C., and Skarabot, J. (2015). Effects of self-myofascial release: a systematic review. J. Bodyw. Mov. Ther. 19, 747-758. doi: 10.1016/j.jbmt.2015.08.007

Born, D. P., Sperlich, B., and Holmberg, H. C. (2013). Bringing light into the dark: effects of compression clothing on performance and recovery. Int. J. Sports Physiol. Perform. 8, 4-18. doi: 10.1123/ijspp.8.1.4

Buchheit, M., Cormie, P., Abbiss, C. R., Ahmaidi, S., Nosaka, K. K., and Laursen, P. B. (2009). Muscle deoxygenation during repeated sprint running: effect of active vs. passive recovery. Int. J. Sports Med. 30, 418-425. doi: 10.1055/s-0028-1105933

Coffey, V. G., and Hawley, J. A. (2007). The molecular bases of training adaptation. Sports Med. 37, 737-763. doi: 10.2165/00007256-200737090-00001

Duking, P., Holmberg, H. C., and Sperlich, B. (2017). Instant biofeedback provided by wearable sensor technology can help to optimize exercise and prevent injury and overuse. Front. Physiol. 8:167. doi: 10.3389/fphys.2017.00167

Duking, P., Hotho, A., Holmberg, H. C., Fuss, F. K., and Sperlich, B. (2016). Comparison of non-invasive individual monitoring of the training and health of athletes with commercially available wearable technologies. Front. Physiol. 7:71. doi: 10.3389/fphys.2016.00071

Fiskerstrand, A., and Seiler, K. S. (2004). Training and performance characteristics among Norwegian international rowers 1970-2001. Scand. J. Med. Sci. Sports 14, 303-310. doi: 10.1046/j.1600-0838.2003.370.x

Fowler, P. M., McCall, A., Jones, M., and Duffield, R. (2017). Effects of long-haul transmeridian travel on player preparedness: case study of a national team at the 2014 FIFA World Cup. J. Sci. Med. Sport 20, 322-327. doi: $10.1016 /$ j.jsams.2016.08.021

Giles, L. V., and Koehle, M. S. (2014). The health effects of exercising in air pollution. Sports Med. 44, 223-249. doi: 10.1007/s40279-013-0108-z
Thus, it appears virtually impossible to take all of these factors into consideration when studying a homogenous group of elite athletes, not even in a controlled laboratory setting. However, both retro- and prospective analyses on the responses and adaptation to training should provide as much information about such modulators as possible. In this context, we feel that a combination of wearable technology and smartphonebased applications should prove invaluable, since this is the only technology that currently allows as much information as possible to be obtained by continuous $24-\mathrm{h}$ monitoring of, in addition to the internal and external training loads themselves, sleep, traveling, various environmental conditions and psycho-social status. As long as scientific quality is maintained (Duking et al., 2016; Sperlich and Holmberg, 2017) and personal data protected, such technology can potentially provide 24 -h feedback (Duking et al., 2017) to the athlete and supporting staff concerning the various psycho-biological responses to training. In this regards, future findings on "Wearable Sensor Technology for Monitoring Training Load and Health in the Athletic Population" (Frontiers in Physiology, 2017) will hopefully help provide innovative approaches to investigating the "Training intensity, volume and recovery distribution among elite and recreational endurance athletes."

\section{AUTHOR CONTRIBUTIONS}

All authors listed have made a substantial, direct and intellectual contribution to the work, and approved it for publication.

Girard, O., Brocherie, F., and Millet, G. P. (2017). Effects of altitude/hypoxia on single- and multiple-sprint performance: a comprehensive review. Sports Med. doi: 10.1007/s40279-017-0733-z. [Epub ahead of print].

Gupta, L., Morgan, K., and Gilchrist, S. (2017). Does elite sport degrade sleep quality? A systematic review. Sports Med. 47, 1317-1333. doi: 10.1007/s40279016-0650-6

Kanherkar, R. R., Bhatia-Dey, N., and Csoka, A. B. (2014). Epigenetics across the human lifespan. Front. Cell Dev. Biol. 2:49. doi: 10.3389/fcell.2014.00049

Kölling, S., Treff, G., Winkert, K., Ferrauti, A., Meyer, T., Pfeiffer, M., et al. (2016). The effect of westward travel across five time zones on sleep and subjective jet-lag ratings in athletes before and during the 2015's World Rowing Junior Championships. J. Sports Sci. doi: 10.1080/02640414.2016.1265141. [Epub ahead of print].

Kruger, M., de Marees, M., Dittmar, K. H., Sperlich, B., and Mester, J. (2015). Whole-body cryotherapy's enhancement of acute recovery of running performance in well-trained athletes. Int. J. Sports Physiol. Perform. 10, 605-612. doi: 10.1123/ijspp.2014-0392

Laursen, P. B., and Jenkins, D. G. (2002). The scientific basis for highintensity interval training: optimising training programmes and maximising performance in highly trained endurance athletes. Sports Med. 32, 53-73. doi: 10.2165/00007256-200232010-00003

Lorenzo, S., Halliwill, J. R., Sawka, M. N., and Minson, C. T. (2010). Heat acclimation improves exercise performance. J. Appl. Physiol. (1985) 109, 1140-1147. doi: 10.1152/japplphysiol.00495.2010

Nedelec, M., Halson, S., Abaidia, A. E., Ahmaidi, S., and Dupont, G. (2015). Stress, sleep and recovery in elite soccer: a critical review of the literature. Sports Med. 45, 1387-1400. doi: 10.1007/s40279-015-0358-Z

Frontiers in Physiology (2016). Training Intensity, Volume and Recovery Distribution among Elite and Recreational Endurance Athletes. Available online at: http://journal.frontiersin.org/researchtopic/4444/trainingintensity-volume-and-recovery-distribution-among-elite-and-recreationalendurance-athletes 
Frontiers in Physiology (2017). Wearable Sensor Technology for Monitoring Training Load and Health in the Athletic Population [Online]. Available online at: http://journal.frontiersin.org/researchtopic/5516/wearable-sensortechnology-for-monitoring-training-load-and-health-in-the-athleticpopulation [accessed].

Poppendieck, W., Faude, O., Wegmann, M., and Meyer, T. (2013). Cooling and performance recovery of trained athletes: a meta-analytical review. Int. J. Sports Physiol. Perform. 8, 227-242.

Poppendieck, W., Wegmann, M., Ferrauti, A., Kellmann, M., Pfeiffer, M., and Meyer, T. (2016). Massage and performance recovery: a meta-analytical review. Sports Med. 46, 183-204. doi: 10.1007/s40279-015-0420-x

Riganas, C. S., Papadopoulou, Z., Psichas, N., Skoufas, D., Gissis, I., Sampanis, M., et al. (2015). The rate of lactate removal after maximal exercise: the effect of intensity during active recovery. J. Sports Med. Phys. Fitness 55, 1058-1063.

Sperlich, B., and Holmberg, H.-C. (2017). Wearable, yes, but able...?: it is time for evidence-based marketing claims! Br. J. Sports Med. 51:1240. doi: 10.1136/bjsports-2016-097295

Sperlich, B., Zinner, C., Hauser, A., Holmberg, H. C., and Wegrzyk, J. (2017). The impact of hyperoxia on human performance and recovery. Sports Med. 47, 429-438. doi: 10.1007/s40279-016-0590-1
Thomas, D. T., Erdman, K. A., and Burke, L. M. (2016). American College of Sports Medicine Joint Position Statement. Nutrition and Athletic Performance. Med. Sci. Sports Exerc. 48, 543-568. doi: 10.1249/MSS.00000000000 00852

Weiler, R., Aggio, D., Hamer, M., Taylor, T., and Kumar, B. (2015). Sedentary behaviour among elite professional footballers: health and performance implications. BMJ Open Sport Exerc. Med. 1:e000023. doi: 10.1136/bmjsem-2015-000023

Conflict of Interest Statement: The authors declare that the research was conducted in the absence of any commercial or financial relationships that could be construed as a potential conflict of interest.

Copyright $\odot 2017$ Sperlich and Holmberg. This is an open-access article distributed under the terms of the Creative Commons Attribution License (CC BY). The use, distribution or reproduction in other forums is permitted, provided the original author(s) or licensor are credited and that the original publication in this journal is cited, in accordance with accepted academic practice. No use, distribution or reproduction is permitted which does not comply with these terms. 